\section{Malignant catarrhal fever infection in a heifer in Jordan}

Sameeh M. Abutarbush

Department of Veterinary Clinical

Sciences, Faculty of Veterinary Medicine,

Jordan University of Science and

Technology, Irbid, Jordan; Veterinary

Medicine Department, College of Food

and Agriculture, United Arab Emirates

University, Al Ain, United Arab Emirates

\begin{abstract}
A 14-month-old Holstein Friesian heifer was presented for decreased appetite, ocular discharge, and diarrhea. The heifer was raised at the farm since she was 3 days old. On presentation, the heifer had bilateral mucopurulent ocular discharge and corneal opacity, ulcerative and necrotic skin, and enlarged superficial lymph nodes. Malignant catarrhal fever (MCF) infection was diagnosed based on clinical signs and PCR. MCF infection has never been reported in Jordan.
\end{abstract}

\section{Introduction}

Malignant catarrhal fever (MCF) is a serious infectious disease of cattle and other ungulates. ${ }^{1}$ Although sporadic in nature, it usually causes a fatal and generalized disease. ${ }^{2}$ MCF is caused by the ruminant -herpesviruses Alcelaphine herpesvirus 1 (AlHV-1) and Ovine herpesvirus 2 (0vHV-2). ${ }^{1}$ The first virus causes the wildebeest (or African)-associated MCF, and the latter causes the sheepassociated MCF, respectively. 3,4 Clinically, affected animals are not usually the source of the infection and the virus is excreted by the natural hosts of both forms, wildebeest and sheep, respectively. ${ }^{2}$ Wildebeest-associated MCF is mainly present in Africa and zoological collections where wildebeest is present.5,6 Sheep-associated MCF is found worldwide wherever sheep and cattle are raised together. ${ }^{1}$

$\mathrm{MCF}$ has a wide range of clinical signs ranging from peracute to chronic illness. ${ }^{2}$ High fever, depression, lack of appetite, mucopurulent ocular and nasal discharges, corneal opacity, enlarged superficial lymph nodes, skin ulceration and exudation, erosions of the buccal cavity and muzzle, diarrhea, and nervous signs can all be seen in cases affected with MCF. ${ }^{2}$ Diagnosis of the diseases is usually based on characteristic clinical signs, histopathological examination, detection of antibodies against MCF virus in blood, or iden- tification of the virus DNA in blood or tissue samples. ${ }^{1}$

Clinical signs of MCF can resemble those of prevalent vesicular/ulcerative/erosive diseases in the Middle East region. Those include foot and mouth disease (FMD), bovine virus diarrhea (BVD), bluetongue (BT), and infectious bovine rhinotracheitis (IBR). A recent article has reported malignant catarrhal fever disease outbreak in a private beef cattle holding in the west bank, which is a neighboring country to Jordan. ${ }^{7}$ However, the disease has never been reported. This case report documents a clinical MCF infection in Jordan for the first time.

\section{Case Report}

A fourteen months old Holstein Friesian heifer was presented to the Veterinary Health Center, Jordan University of Science and Technology for decreased appetite, ocular discharge, and diarrhea. The heifer belonged to a small farm that contains 5 heifers and 5 bull calves. They were bought from several sources including dairy farms and the auction market. The heifer was bought when she was 3 days old and raised at the farm. She was vaccinated for enterotoxaemia, FMD, and was given ivermectin regularly. The diseases started two weeks before presentation where the heifer had ocular and nasal discharge as well as dark color diarrhea. The heifer appetite started to decrease since she became sick. The owner treated the heifer with ophthalmic antibiotic ointment, vitamin A, and systemic antibiotic and anti- inflammatory drug; no improvement was noticed. On presentation, the heifer was in a poor body condition. She was depressed, but alert and responsive. Her temperature was $40.6^{\circ} \mathrm{C}$, heart rate $100 \mathrm{beat} / \mathrm{min}$, and respiratory rate 100 breaths/min. Her eyes were sunken and upper and lower eyebrows were crusty and looked thickened. There was severe bilateral mucopurulent ocular discharge, the skin over the tear track was ulcerative and necrotic, and significant corneal opacity was present (Figures 1 and 2). The heifer was drooling bad odor saliva, but the oral cavity did not have noticeable lesions. She had dark color diarrhea and weak rumen contractions. The muzzle had a thick crust. The skin over the coronary bands of the four limbs was necrotic and ulcerative, and one of the dewclaws was sloughed (Figures 3 and 4). All superficial lymph nodes were enlarged including pre-scapular and prefemoral ones.

A venous blood sample was submitted for complete blood count, fibrinogen, and serum biochemistry. Results of hematological and serum biochemichal examination revealed no significant changes. Parasitological examination of a fecal sample revealed no significant
Correspondence: Sameeh M. Abutarbush, Department of Veterinary Clinical Sciences, Faculty of Veterinary Medicine, Jordan University of Science and Technology, Irbid 22110, Jordan. Tel.: + 96.279.6620635.

E-mail: sameeh75@hotmail.com

Key words: Malignant catarrhal fever; Cattle; Jordan; Infectious diseases; Herpesvirus.

Acknowledgements: the authors would like to thank Dr. Mustafa Ababneh, molecular virology laboratory, Jordan University of Science and Technology for performing the PCR tests.

Contributions: the authors contributed equally.

Conflict of interest: the authors declare no potential conflict of interest.

Received for publication: 12 September 2015. Accepted for publication: 21 October 2015.

This work is licensed under a Creative Commons Attribution NonCommercial 4.0 License (CC BYNC 4.0).

(C) Copyright S.M. Abutarbush, 2016

Licensee PAGEPress srl, Italy

Veterinary Science Development 2016; 6:6203 doi:10.4081/vsd.2016.6203

findings. Considering the clinical signs of bilateral ocular discharge and corneal opacity, enlarged lymph nodes and necrotic and ulcerative lesions of the skin, MCF infection was suspected and a whole blood sample was submitted for MCF PCR. Since there are other diseases that are considered in the differential diagnoses list for such clinical signs, which are present in the region, a blood sample was sent also for PCR testing of FMD, BVD, BT, and IBR. For MCF PCR testing, DNA was extracted from the white blood cells of the buffy coat. PCR assay targeting a DNA fragment in the OvHV-genome was used in this study. PCR primers were: the 556 primer (5' AGTCTGGGGTATATGAATCCAGATGGCTCTC3 '), the 775 primer (5'-AAGATAAGCACCAGTTATGCATCTGATAAA-3'), ${ }^{8}$ to get a PCR product of $422 \mathrm{bp}$.

Based on the poor prognosis, the owner was advised to euthanize the heifer, but he did not approve. The heifer was discharged with a recommendation to give her IV fluids, systemic antibiotics and anti-inflammatory drug by the local veterinarian. The heifer did not improve and the owner decided finally to euthanize her. He was asked to bring her to our center to do a full post mortem examination, but unfortunately he did not comply. PCR results were positive for MCF virus (Figure 5) and negative for FMD, BT, BVD, and IBR viruses. 


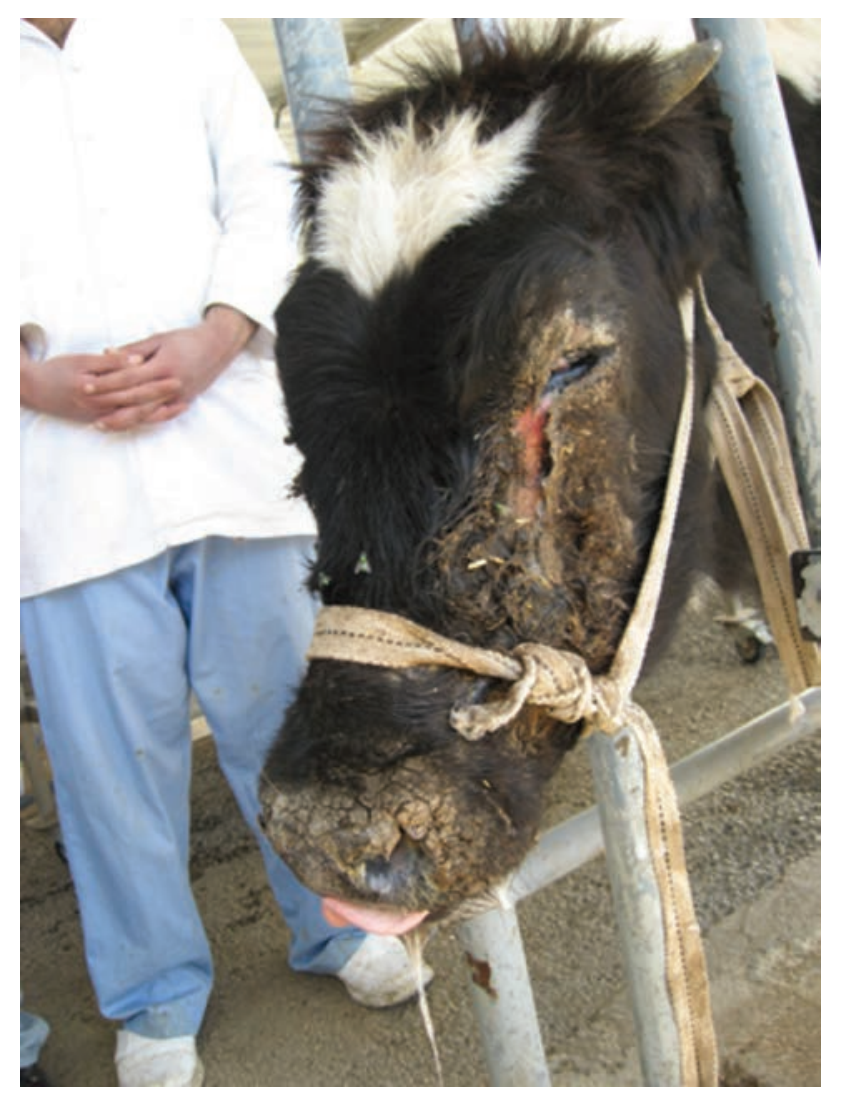

Figure 1. Mucopurulent ocular discharge, crusty muzzle and eyebrows in a heifer affected with malignant catarrhal fever in Jordan.

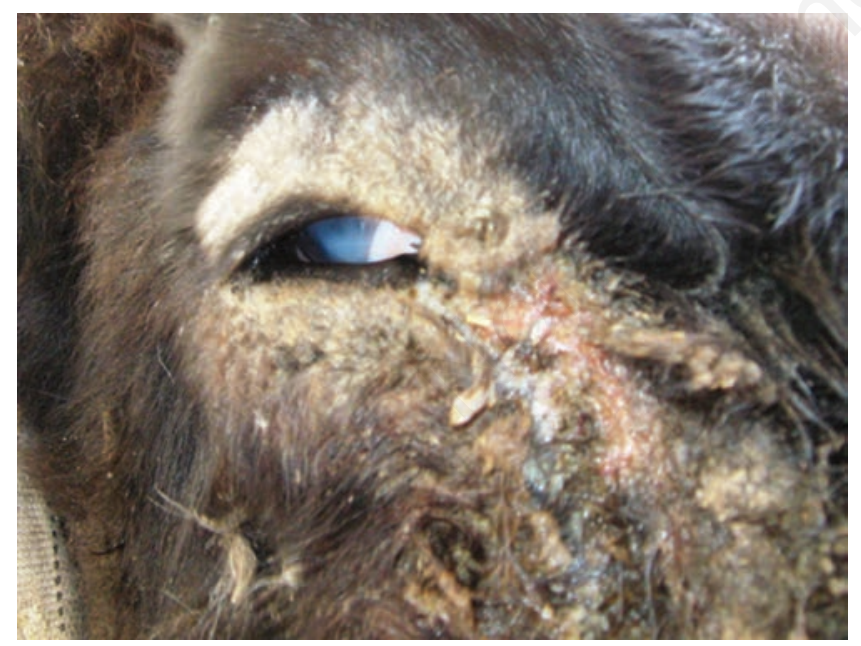

Figure 2. Corneal opacity in a heifer affected with malignant catarrhal fever in Jordan.

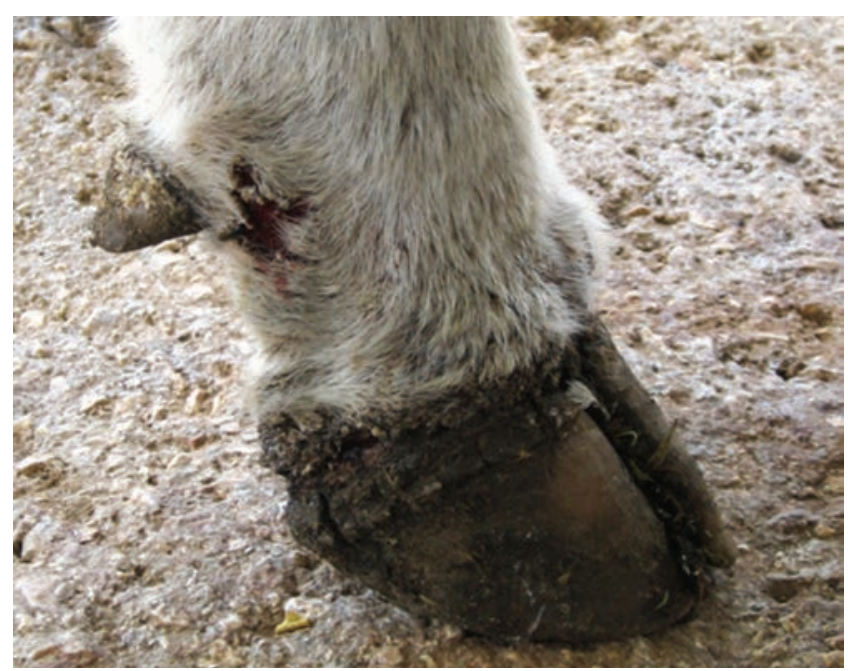

Figure 3. Necrotic and ulcerative skin over the coronary band of a heifer affected with malignant catarrhal fever in Jordan.

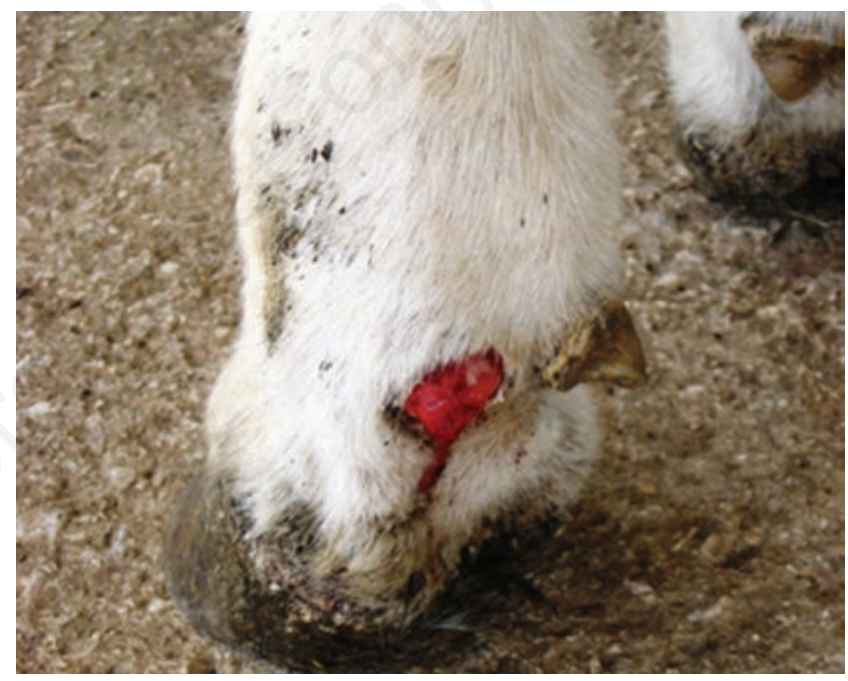

Figure 4. Sloughed dewclaw in a heifer affected with malignant catarrhal fever in Jordan.

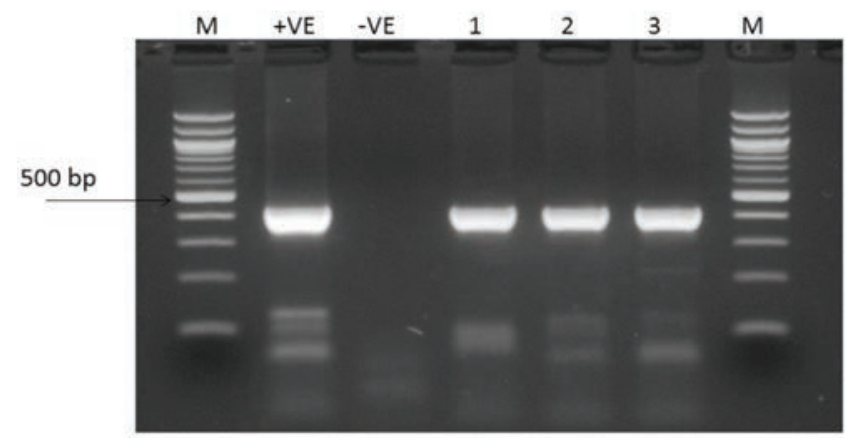

Figure 5. An image of PCR test result done on a blood sample of a heifer affected with malignant catarrhal fever in Jordan. Gel electrophoresis for PCR amplification of a fragment of OvHV. M is the $\mathbf{1 0 0} \mathrm{bp}$ DNA ladder, +ve is a positive control sample, -ve is a negative control sample, 1,2 and 3 are blood samples obtained from the heifer and are positive for OvHV. 


\section{Discussion and Conclusions}

Malignant catarrhal fever has never been reported in Jordan and this is the first study that documents its presence in the country. The clinical signs were typical of those seen in clinical infection of MCF and the disease was confirmed by PCR.

There are two types of MCF infection: wildebeest and sheep-associated MCF. It was likely that the type seen in this heifer is sheep-associated because wildebeest associated is restricted to Africa and zoological collections where wildebeest is present.5,6 Furthermore sheep-associated MCF is present worldwide and it is not uncommon in Jordan to find sheep being raised in a close proximity of cattle holdings. ${ }^{1}$ When the owner was asked about the presence of sheep flocks in his farm area, he indicated that he and his neighbor raise sheep. Also, some of the animals in his farm were bought from the auction market were cattle and sheep are comingled before they are sold. On the other hand, there was a recent outbreak that was reported in the west bank, which is a country near to Jordan. ${ }^{7}$ In that study, molecular characterization of the MCF virus isolates were confirmed as 0vHV-2.

Ulcerative, erosive and vesicular infectious diseases are known to be present in our region. Those include BVD, FMD, BT, and IBR. This case report should be of a great value to the food animal practioners in the country and region. Once encountered with animals showing clinical signs suggestive of an ulcerative/erosive/vesicular disease, MCF should be added to the differential diagnoses list along with the previously mentioned diseases. There are similarities in the clinical signs manifested by these diseases and MCF; however, some clinical signs are characteristic for certain diseases. MCF is known to cause swollen lymph nodes and cutaneous vasculitis, as seen in this case. Those two signs are not usually seen in BVD, FMD, BT, or IBR. Clinical BT is mainly seen in sheep and FMD occurs as epidemics and causes high mortalities in neonates. IBR is usually associated with abortion and respiratory signs are the main presenting complaint. BVD infection produces a wide spectrum of clinical signs, but usually affected cases are presented with diarrhea and no swollen lymph nodes or corneal opacity is seen, as in cases affected by MCF.

More transboundary infectious diseases are being reported in different countries in the region. This necessitates a wide range surveillance studies to be conducted in the region to map and identify those important diseases in order to control them and prevent their spread.

\section{References}

1. Russell GC, Stewart JP, Haig DM. Malignant catarrhal fever: a review. Vet J
2009;179:324-35.

2. Malignant catarrhal fever. In: OIE Manual of Diagnostic Tests and Vaccines for Terrestrial Animal. $5^{\text {th }}$ ed. OIE Biological Standards Commission: Paris, France; 2004. pp 570-9.

3. Plowright W, Ferris RD, Scott GR. Blue wildebeest and the aetiological agent of bovine malignant catarrhal fever. Nature 1960;188:1167-9.

4. McGeoch DJ, Gatherer D, Dolan A. On phylogenetic relationships among major lineages of the Gammaherpesvirinae. J General Virol 2005;86:307-16.

5. Bedelian C, Nkedianye D, Herrero M. Maasai perception of the impact and incidence of malignant catarrhal fever (MCF) in southern Kenya. Prev Vet Med 2007;78:296-316.

6. Whitaker KA, Wessels ME, Campbell I, Russell GC. An outbreak of wildebeestassociated malignant catarrhal fever in Ankole cattle. Vet Rec 2007;161:692-95.

7. Ababneh MM, Hananeh WM, Dalab AE. Molecular and histopathological characterization of sheep-associated malignant catarrhal fever (SA-MCF) outbreak in beef cattle. Transbound Emerg Dis 2014;61:7580.

8. Baxter SI, Pow I, Bridgen A, Reid HW. PCR detection of the sheep associated agent of malignant catarrhal fever. Arch Virol 1993;132:145-59. 